\title{
Author Correction: Hippocampus-driven feed-forward inhibition of the prefrontal cortex mediates relapse of extinguished fear
}

Roger Marek (D), Jingji Jin, Travis D. Goode (1), Thomas F. Giustino (D), Qian Wang, Gillian M. Acca, Roopashri Holehonnur, Jonathan E. Ploski, Paul J. Fitzgerald, Timothy Lynagh (D), Joseph W. Lynch (D), Stephen Maren (1) and Pankaj Sah (D)

Correction to: Nature Neuroscience https://doi.org/10.1038/s41593-018-0073-9, published online 5 February 2018.

In the version of this article initially published, the traces in Fig. $1 \mathrm{j}$ and in Fig. 1k, right, were duplicated from the corresponding traces in Fig. 1c, bottom, and Fig. 1d, bottom right. The error has been corrected in the HTML and PDF versions of the article.

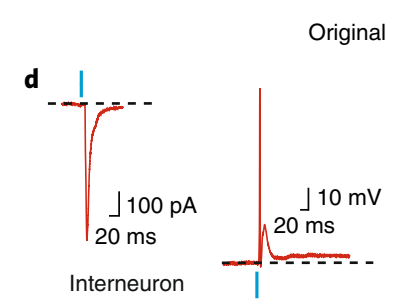

j
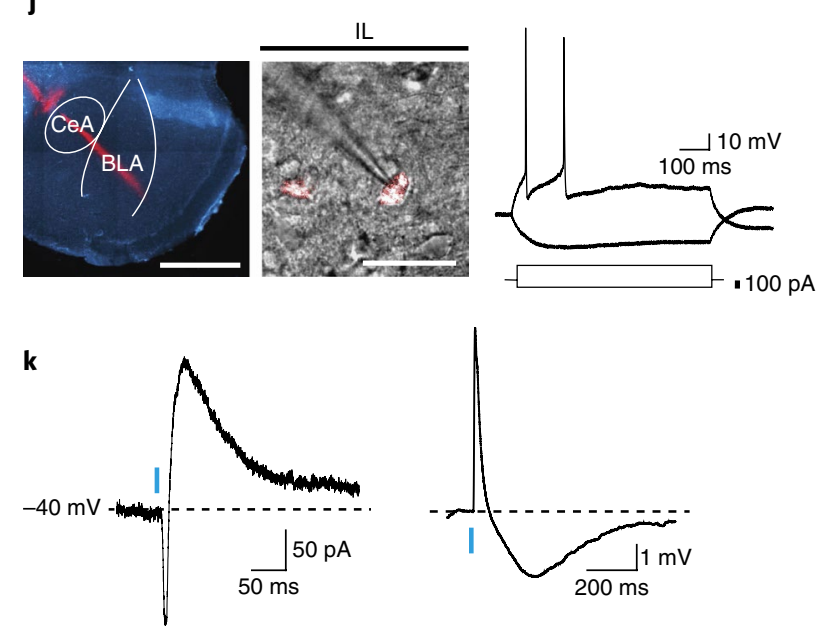

Fig. 1j,k | Original and corrected.

Published online: 9 July 2018

https://doi.org/10.1038/s41593-018-0183-4
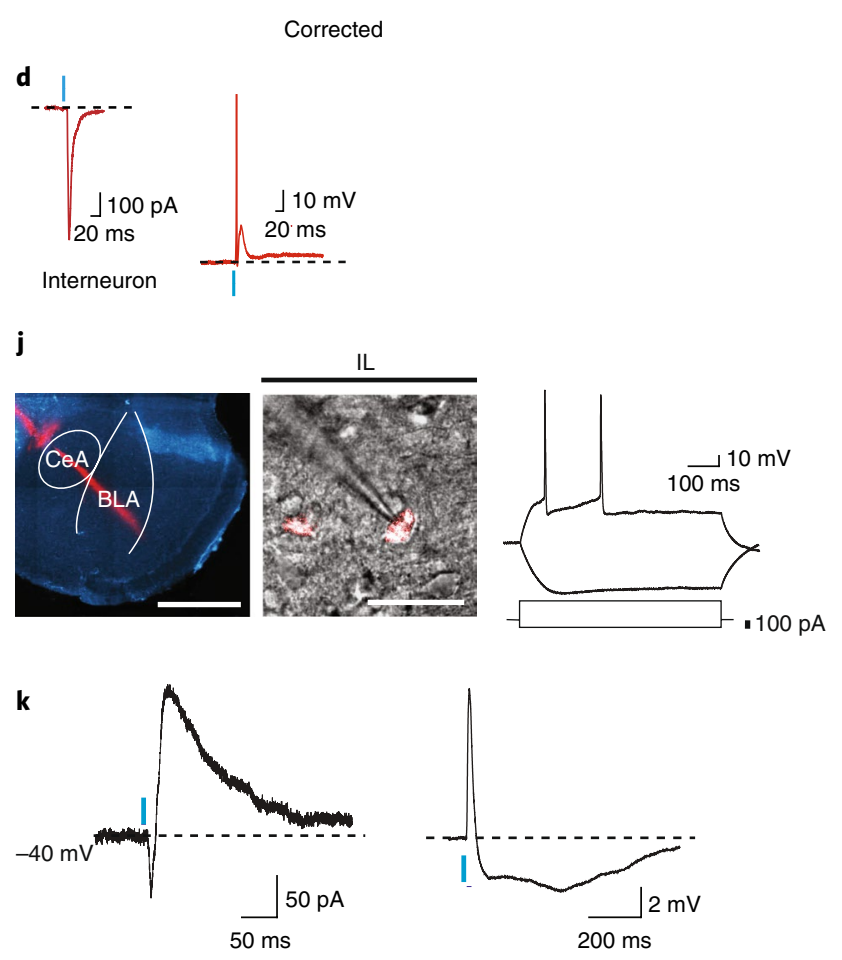

\section{Author Correction: Transneuronal propagation of mutant huntingtin contributes to non- cell autonomous pathology in neurons}

Eline Pecho-Vrieseling, Claus Rieker, Sascha Fuchs, Dorothee Bleckmann, Maria Soledad Esposito, Paolo Botta, Chris Goldstein, Mario Bernhard, Ivan Galimberti, Matthias Müller, Andreas Lüthi, Silvia Arber, Tewis Bouwmeester, Herman van der Putten and Francesco Paolo Di Giorgio

Correction to: Nature Neuroscience https://doi.org/10.1038/nn.3761, published online 13 July 2014.

In the version of this article initially published, the catalog numbers for BoNT A and B were given in the Methods section as T0195 and T5644; the correct numbers are B8776 and B6403. The error has been corrected in the HTML and PDF versions of the article. 